\title{
KARAKTERISTIK OPERATOR HIPONORMAL-p \\ PADA RUANG HILBERT
}

\author{
Gunawan \\ Universitas Muhammadiyah Purwokerto \\ Email: gun.oge@gmail.com
}

\begin{abstract}
ABTRACT. This article discusses the definition and properties of p-hiponormal operators for $p>0$. To investigate the properties of p-hiponormal operators, the concept of positive operators, partial isometry operators, decomposition of operators, and existence of partial isometry operators for any operator on a Hilbert space are required.
\end{abstract}

ABTRAK. Pada artikel ini akan dibahas mengenai definisi dan beberapa sifat-sifat operator hiponormal-p, untuk $p>0$. Untuk menyelidiki sifat-sifat operator hiponormal-p diperlukan konsep operator positif, operator isometri parsial, dekomposisi sebarang operator, dan eksistensi operator isometri parsial untuk sebarang operator pada ruang Hilbert.

Kata Kunci: Ruang Hilbert, Operator Positif, Dekomposisi Operator, Operator Hiponormal-p.

\section{PENDAHULUAN}

\section{a. Latar Belakang dan Permasalahan}

Diberikan ruang Hilbert $H$ atas lapangan $F$, himpunan semua operator linear terbatas dari $H$ ke $H$ ditulis $B(H)$, dan $T \in B(H)$. Lapangan $F$ yang dimaksudkan di tulisan ini adalah $\mathbb{C}$ (himpunan bilangan Kompleks). Operator $T$ dapat didekomposisikan menjadi $T=U|T|$ dengan $U: H \rightarrow H$ operator isometri parsial dan $|T|$ akar kuadrat positif dari $T^{*} T$. Selanjutnya, untuk bilangan $p>0$, operator linear kontinu $T$ yang memiliki sifat $\left(T^{*} T\right)^{p} \geq\left(T T^{*}\right)^{p}$ atau $|T|^{2 p} \geq\left|T^{*}\right|^{2 p}$, dengan $|T|^{2}=T^{*} T$ disebut sebagai operator hiponormal- $p$. Untuk $p=1$, operator $T$ disebut operator hiponormal dan untuk $p=\frac{1}{2}$, operator $T$ disebut operator semihiponormal. Untuk $0<p<1$, operator hiponormal-p telah diteliti oleh beberapa 
matematikawan, diantaranya Aluthge (1999), Duggal (1995), dan Xia (1980). Dalam Aluthge (1999), disebutkan bahwa apabila $T$ operator hiponormal- $p$ dan $T=U|T|$ dekomposisi dari $T$ dengan $U$ operator isometri parsial, maka operator $\tilde{T}=|T|^{\frac{1}{2}} U|T|^{\frac{1}{2}}$ disebut transformasi Aluthge. Selain itu, dalam Aluthge (1999), disebutkan bahwa untuk $p>0$, apabila $T$ hiponormal- $p$ maka, untuk $0<p<\frac{1}{2}$, $\tilde{T}=|T|^{\frac{1}{2}} U|T|^{\frac{1}{2}}$ hiponormal- $\left(p+\frac{1}{2}\right)$.

Hal tersebut kemudian membawa pemikiran untuk menyelidiki karakteristik operator $T$ yang memiliki sifat $\left(T^{*} T\right)^{p} \geq\left(T T^{*}\right)^{p}$. Pembahasan mengenai karakteristik operator hiponormal- $p$ pada tulisan ini, lebih ditekankan pada memahami definisi dan sifat- sifat operator hiponormal- $p$ pada ruang Hilbert.

\section{b. Tujuan dan Manfaat Penelitian}

Tujuan penelitian ini adalah untuk memberikan pemahaman dan pengetahuan mengenai sifat- sifat dan karakteristik operator hiponormal- $p(p>0)$ pada ruang Hilbert. Pembahasan mengenai operator hiponormal- $p$ pada ruang Hilbert bermanfaat membantu mengembangkan ilmu matematika dan aplikasinya, khususnya analisis fungsional.

\section{KARAKTERISTIK OPERATOR HIPONORMAL- $p$}

Pada bagian ini dibahas mengenai definisi dan sifat- sifat operator hiponormal- $p$ pada ruang Hilbert, operator positif, serta dekomposisi operator.

Berikut ini akan dibahas definisi operator hiponormal- $p$ dan konsep dasar operator hiponormal- $p$ pada ruang Hilbert.

Definisi 2.1. Diketahui $H$ ruang Hilbert atas $F$ dan $T \in B(H)$. Untuk $p>0$, operator $T$ dikatakan hiponormal-p jika $\left(T^{*} T\right)^{p} \geq\left(T T^{*}\right)^{p}$. 
Untuk $p>0$, sifat $\left(T^{*} T\right)^{p} \geq\left(T T^{*}\right)^{p}$ ekuivalen dengan sifat $|T|^{2 p} \geq\left|T^{*}\right|^{2 p}$ dengan $|T|^{2}=T^{*} T$ dan $\left|T^{*}\right|^{2}=\left(T^{*}\right)^{*} T^{*}=T T^{*}$.

Selanjutnya, akan dibahas mengenai operator positif. Operator positif ini akan digunakan untuk membuktikan sifat-sifat operator hiponormal-p.

Definisi 2.2. Diketahui $H$ ruang Hilbert atas $F$ dan $T \in B(H)$. Operator $T$ dikatakan positif jika $\langle T(x), x\rangle \geq 0$, untuk setiap $x \in H$. Selanjutnya operator positif $T$ dinotasikan dengan $T \geq 0$.

Lemma 2.3 (Kreyszig, 1978). Diketahui $H$ ruang Hilbert atas $F$ dan $T \in B(H)$. Jika $T \geq 0$ maka $T=T^{*}$ (self adjoint).

Setelah disampaikan mengenai operator positif, berikut ini akan dibahas mengenai eksistensi akar kuadrat positif dari operator positif.

Diketahui $H$ ruang Hilbert atas $F$ dan $T \in B(H)$ adalah operator positif. $S \in B(H)$ disebut akar kuadrat operator $T$ jika $S^{2}=T$ dan dinotasikan dengan operator $S=T^{\frac{1}{2}}$.

Teorema 2.4 (Kreyszig, 1978). Diketahui $H$ ruang Hilbert atas $F$ dan $T \in B(H)$. Jika $T$ adalah self adjoint maka terdapat secara tunggal operator positif $S$ sehingga $T=S^{2}$.

Selanjutnya, dipahami bahwa $A \geq B \geq 0 \Leftrightarrow A-B \geq 0$, yang berarti untuk sebarang $x \in H$,

$$
\begin{aligned}
& \langle(A-B)(x), x\rangle \geq 0 \\
& \Leftrightarrow\langle A(x)-B(x), x\rangle \geq 0 \\
& \Leftrightarrow\langle A(x), x\rangle-\langle B(x), x\rangle \geq 0 \\
& \Leftrightarrow\langle A(x), x\rangle \geq\langle B(x), x \cdot\rangle .
\end{aligned}
$$


Lebih lanjut, untuk $T \in B(H)$ dan $T$ adalah operator positif, definisikan, untuk $\alpha \in[0,1]$

$$
T^{\alpha}=\left(\sum_{i=1}^{\infty} \lambda_{i} p_{i}\right)^{\alpha}
$$

dengan $\left(\lambda_{i}\right)$ dan $\left(p_{i}\right)$ masing-masing adalah barisan bilangan kompleks dan barisan proyeksi ortogonal.

Teorema 2.5 (Ketaksamaan Lowner- Heinz) (Furuta, 2002). Diketahui $H$ ruang Hilbert atas $F$ dan $A, B \in B(H)$. Jika $A \geq B \geq 0$ maka untuk setiap $\alpha \in[0,1]$ berlaku $A^{\alpha} \geq B^{\alpha} \geq 0$.

Selanjutnya, Teorema 2.5 akan digunakan untuk membuktikan teorema berikut, yang merupakan sifat-sifat operator hiponormal- $p$.

Teorema 2.6 (Yuan dan Yang, 2006). Jika untuk $p>0, T$ adalah operator hiponormal- $p$ maka, untuk $0<q \leq p, T$ merupakan operator hiponormal- $q$.

Bukti : Perhatikan bahwa

$$
\left(T^{*} T\right)^{q}=\left(|T|^{2}\right)^{q}=\left(\left(|T|^{2}\right)^{p}\right)^{\frac{q}{p}}
$$

dan

$$
\left(T T^{*}\right)^{q}=\left(\left|T^{*}\right|^{2}\right)^{q}=\left(\left(\left|T^{*}\right|^{2}\right)^{p}\right)^{\frac{q}{p}} .
$$

Diketahui $T$ adalah hiponormal- $p$, yang berarti $\left(T^{*} T\right)^{p} \geq\left(T T^{*}\right)^{P}$. Menurut Teorema 2.5, diperoleh

$$
\left(\left(|T|^{2}\right)^{p}\right)^{\alpha} \geq\left(\left(\left|T^{*}\right|^{2}\right)^{p}\right)^{\alpha}
$$


untuk setiap $\alpha \in[0,1]$ dan jelas bahwa $|T|^{2},\left|T^{*}\right|^{2}$ merupakan operator positif. Selanjutnya, diketahui bahwa $0<q \leq p$, yang berarti $0<\frac{q}{p}<1$. Ambil $\alpha=\frac{q}{p}$. Jadi $\alpha \in[0,1]$ dan

$$
\begin{aligned}
& \left(\left(|T|^{2}\right)^{p}\right)^{\frac{q}{p}} \geq\left(\left(\left|T^{*}\right|^{2}\right)^{p}\right)^{\frac{q}{p}} \\
& \Leftrightarrow\left(|T|^{2}\right)^{q} \geq\left(\left|T^{*}\right|^{2}\right)^{q} \\
& \Leftrightarrow\left(T^{*} T\right)^{q} \geq\left(T T^{*}\right)^{q} .
\end{aligned}
$$

Dengan demikian, $T$ hiponormal- $q$.

Selanjutnya, akan diberikan definisi mengenai operator isometri parsial. Konsep mengenai isometri parsial digunakan dalam pendefinisian dekomposisi operator. Dalam definisi berikut, dipahami bahwa himpunan $M^{\perp}$ merupakan komplemen ortogonal dari himpunan $M$.

Definisi 2.7. Diketahui $H$ ruang Hilbert atas $F$. Operator $T \in B(H)$ dikatakan isometri parsial jika terdapat ruang bagian tertutup $M \subseteq H$ sehingga $\|T(x)\|=\|x\|, \forall x \in M$ dan $T(x)=0, \forall x \in M^{\perp}$.

Selanjutnya, akan diberikan teorema mengenai eksistensi operator isometri parsial untuk sebarang operator. Dalam teorema berikut, $R(T)$ dan $R(S)$ masingmasing menyatakan daerah hasil (Range) operator $T$ dan $S$.

Teorema 2.8 (Furuta,2002). Diketahui $H$ ruang Hilbert dan $S, T \in B(H)$. Jika $T^{*} T=S^{*} S$ maka terdapat operator isometri parsial $U$ sehingga $S=U T$.

Bukti : Diketahui $T^{*} T=S^{*} S$. Untuk setiap $x \in H$ :

$$
\|T(x)\|^{2}=\langle T(x), T(x)\rangle=\left\langle T^{*} T(x), x\right\rangle=\left\langle S^{*} S(x), x\right\rangle=\langle S(x), S(x)\rangle=\|S(x)\|^{2} .
$$

Jika $T\left(x_{1}\right)=T\left(x_{2}\right)$ untuk setiap $x_{1}, x_{2} \in H$ maka :

$$
0=\left\|T\left(x_{1}\right)-T\left(x_{2}\right)\right\|=\left\|T\left(x_{1}-x_{2}\right)\right\|=\left\|S\left(x_{1}-x_{2}\right)\right\|=\left\|S\left(x_{1}\right)-S\left(x_{2}\right)\right\| .
$$


Diperoleh $S\left(x_{1}\right)=S\left(x_{2}\right)$. Definisikan operator $V: R(T) \rightarrow R(S)$ dengan

$$
V(T(x))=S(x), \forall x \in H .
$$

Diperoleh $V$ adalah linear, terbatas, dan $\|V T(x)\|=\|S(x)\|=\|T(x)\|$. Jadi, $V$ adalah isometri. Selanjutnya, definisikan operator $\tilde{V}: \overline{R(T)} \rightarrow \overline{R(S)}$ dengan

$$
\tilde{V}(y)=\lim V\left(y_{n}\right), \forall y \in \overline{R(T)},\left(y_{n}\right) \subseteq R(T), y_{n} \rightarrow y .
$$

Diperoleh $\tilde{V}$ linear dan terbatas. Untuk setiap $n \in \mathbb{N}$ (himpunan bilangan Asli), $y_{n} \in R(T)$, yang berarti terdapat $x_{n} \in D(T)$ sehingga $T\left(x_{n}\right)=y_{n}$. Lebih lanjut,

$$
\|\tilde{V}(y)\|=\lim \left\|V\left(y_{n}\right)\right\|=\lim \left\|V T\left(x_{n}\right)\right\|=\lim \left\|S\left(x_{n}\right)\right\|=\lim \left\|T\left(x_{n}\right)\right\|=\lim \left\|y_{n}\right\|=\|y\| .
$$

Diperoleh $\tilde{V}$ isometri.

Definisikan operator $U: H \rightarrow H$ dengan

$$
U(x)=\tilde{V} P_{M}(x), \forall x \in H
$$

dan $P_{M}$ adalah proyeksi ortogonal pada $M$, dengan $M=\overline{R(T)}$. Jika $x \in M$ maka $P_{M}(x)=x \quad$ dan $\quad\|U(x)\|=\left\|\tilde{V} P_{M}(x)\right\|=\|\tilde{V}(x)\|=\|x\| . \quad$ Jika $\quad x \in M^{\perp} \quad$ maka $U(x)=\tilde{V} P_{M}(x)=\tilde{V}(0)=0 . \quad$ Jadi, $\quad U$ adalah isometri parsial. Karena $R(U)=U(H)=\tilde{V} P_{M}(H)=\tilde{V}(M)$, maka untuk setiap $x \in H$,

$$
U T(x)=\tilde{V} P_{M}(T(x))=\tilde{V} T(x)=S(x)
$$

Jadi, $S=U T$.

Teorema 2.9 (Furuta, 2002). Diketahui $H$ ruang Hilbert atas $F$. Jika $T \in B(H)$ maka terdapat operator isometri parsial $U$ sehingga $T=U|T|$ dengan $|T|=\left(T^{*} T\right)^{\frac{1}{2}}$. Lebih lanjut, $T=U|T|$ disebut dekomposisi dari $T$ pada ruang Hilbert $H$.

Bukti : Ambil sebarang $x \in H$. Karena $\left\langle T^{*} T(x), x\right\rangle=\langle T(x), T(x)\rangle=\|T(x)\|^{2} \geq 0$ diperoleh $\left(T^{*} T\right)$ adalah operator positif. Karena $|T|^{2}=T^{*} T$ adalah positif, maka 
$|T|=\left(T^{*} T\right)^{\frac{1}{2}}$ merupakan operator positif. Karena $|T|$ adalah operator positif, maka $|T|=|T|^{*}$ (self adjoint). Perhatikan bahwa $T^{*} T=|T|^{2}=|T||T|=|T|^{*}|T|$. Menurut

Teorema 2.8, terdapat operator isometri parsial $U$ sehingga $T=U|T|$.

Lemma 2.10 (Furuta, 2002). Diketahui $H$ ruang Hilbert atas $F$ dan $T \in B(H)$. Jika $T=U|T|$ dekomposisi dari $T$ pada ruang Hilbert $H$ maka $\left|T^{*}\right|^{p}=U|T|^{p} U^{*}$ untuk setiap $p>0$.

Bukti: Ambil sebarang $x \in H$. Perhatikan bahwa

$$
\left\langle|T|^{2}(x), x\right\rangle=\left\langle T^{*} T(x), x\right\rangle=\langle T(x), T(x)\rangle=\|T(x)\|^{2} \geq 0 .
$$

Jadi $|T|^{2}$ adalah operator positif. Akibatnya, $|T|$ merupakan operator positif. Kemudian, $T^{*}=(U|T|)^{*}=|T|^{*} U^{*}=|T| U^{*}$, sehingga diperoleh

$$
\left|T^{*}\right|^{2}=T T^{*}=U|T||T| U^{*}=U|T| U^{*} U|T| U^{*}=\left(U|T| U^{*}\right)^{2} .
$$

Untuk setiap $n \in \mathbb{N}$, diperoleh

$$
\begin{aligned}
\left(\left|T^{*}\right|^{2}\right)^{n} & =\left\{\left(U|T| U^{*}\right)^{2}\right\}^{n}=\left(U|T| U^{*} U|T| U^{*}\right)^{n} \\
& =\underbrace{U|T| U^{*} U|T| U^{*} \ldots}_{n \text { faktor }}=\underbrace{U|T||T| U^{*} \ldots}_{n \text { faktor }}=\underbrace{U|T|^{2} U^{*} \ldots}_{n \text { faktor }}=U|T|^{2 n} U^{*} .
\end{aligned}
$$

Selanjutnya akan ditunjukkan $\left|T^{*}\right|^{\frac{n}{m}}=U|T|^{\frac{n}{m}} U^{*}$ untuk setiap $m, n \in \mathbb{N}$.

Ambil sebarang $m, n \in \mathbb{N}$ dan $m$ tetap, diperoleh

1) Untuk $n=1$ diperoleh $\left|T^{*}\right|^{\frac{1}{m}}=U|T|^{\frac{1}{m}} U^{*}$

2) Anggap benar untuk $n=k$, 


$$
\left|T^{*}\right|^{\frac{k}{m}}=U|T|^{\frac{k}{m}} U^{*}
$$

3) Akan dibuktikan benar untuk $n=k+1$,

$$
\left|T^{*}\right|^{\frac{k+1}{m}}=|T|^{\frac{k}{m}}|T|^{\frac{1}{m}}=U|T|^{\frac{k}{m}} U^{*} U|T|^{\frac{1}{m}} U^{*}=U|T|^{\frac{k}{m}} I|T|^{\frac{1}{m}} U^{*}=U|T|^{\frac{k+1}{m}} U^{*}
$$

Jadi $\left|T^{*}\right|^{\frac{n}{m}}=U|T|^{\frac{n}{m}} U^{*}$ untuk setiap $m, n \in \mathbb{N}$. Selanjutnya, dengan sifat kekontinuan, diperoleh

$$
\left|T^{*}\right|^{p}=\lim _{\frac{n}{m} \rightarrow p} U|T|^{\frac{n}{m}} U^{*}=U|T|^{p} U^{*} .
$$

Karena $m, n \in \mathbb{N}$, maka $\frac{n}{m}$ merupakan bilangan rasional. Karena $\frac{n}{m}$ merupakan bilangan rasional dan $\frac{n}{m} \rightarrow p$, maka $p>0$. Jadi $\left|T^{*}\right|^{p}=U|T|^{p} U^{*}$ untuk setiap $p>0$.

Teorema 2.11 (Furuta, 2008). Diketahui $H$ ruang Hilbert atas $F$ dan $T \in B(H)$. Diberikan $T=U|T|$ adalah dekomposisi dari $T$ pada ruang Hilbert $H$. Jika $T$ adalah hiponormal- $p$ maka untuk $0<p<\frac{1}{2}, \tilde{T}=|T|^{\frac{1}{2}} U|T|^{\frac{1}{2}}$ hiponormal- $\left(p+\frac{1}{2}\right)$

Bukti : Diketahui, untuk $p>0, T$ hiponormal- $p$, yang berarti

$$
\left(T^{*} T\right)^{p} \geq\left(T T^{*}\right)^{p} \Leftrightarrow|T|^{2 p} \geq\left|T^{*}\right|^{2 p} .
$$

Perhatikan bahwa

$$
\begin{aligned}
& \left(T^{*} T\right)^{p} \geq\left(T T^{*}\right)^{p} \\
& \Leftrightarrow|T|^{2 p} \geq\left|T^{*}\right|^{2 p} \\
& \Leftrightarrow U^{*}|T|^{2 p} U \geq U^{*}\left|T^{*}\right|^{2 p} U \text {, untuk suatu } U \in B(H) \text { isometri parsial. }
\end{aligned}
$$

Diperoleh

$$
U^{*}|T|^{2 p} U \geq|T|^{2 p}
$$

Lebih lanjut, 


$$
|T|^{2 p} \geq\left|T^{*}\right|^{2 p}=U|T|^{2 p} U^{*}
$$

Untuk setiap $x \in H$

$$
\left\langle U|T|^{2 p} U^{*}(x), x\right\rangle=\left\langle|T|^{2 p} U^{*}(x), U^{*}(x)\right\rangle \geq 0 .
$$

Dari (1), (2), dan (3) diperoleh

$$
U^{*}|T|^{2 p} U \geq|T|^{2 p} \geq U|T|^{2 p} U^{*} \geq 0
$$

Selanjutnya,

$$
\begin{aligned}
\left(\tilde{T}^{*} \tilde{T}\right)^{p+\frac{1}{2}} & =\left(|T|^{\frac{1}{2}} U^{*}|T|^{\frac{1}{2}}|T|^{\frac{1}{2}} U|T|^{\frac{1}{2}}\right)^{p+\frac{1}{2}}=\left(|T|^{\frac{1}{2}} U^{*}|T| U|T|^{\frac{1}{2}}\right)^{p+\frac{1}{2}}=\left(|T|^{\frac{1}{2}}|T||T|^{\frac{1}{2}}\right)^{p+\frac{1}{2}} \\
& \geq\left(|T|^{\frac{1}{2}} U|T| U^{*}|T|^{\frac{1}{2}}\right)^{p+\frac{1}{2}}=\left(|T|^{\frac{1}{2}} U|T|^{\frac{1}{2}}|T|^{\frac{1}{2}} U^{*}|T|^{\frac{1}{2}}\right)^{p+\frac{1}{2}} \\
& =\left(\tilde{T} \tilde{T}^{*}\right)^{p+\frac{1}{2}}
\end{aligned}
$$

Jadi, $\tilde{T}$ hiponormal- $\left(p+\frac{1}{2}\right)$.

\section{KESIMPULAN DAN SARAN}

\subsection{Kesimpulan}

Berdasarkan pembahasan di atas, maka kesimpulan yang dapat diambil adalah jika diberikan $H$ ruang Hilbert atas $F$ maka, untuk bilangan $p>0$, operator linear kontinu $T$ dikatakan hiponormal- $p$ apabila operator $T$ memenuhi sifat $\left(T^{*} T\right)^{p} \geq\left(T T^{*}\right)^{p}$. Lebih lanjut, untuk $p>0$, jika $T$ operator hiponormal- $p$ maka, untuk $0<q \leq p, T$ merupakan operator hiponormal- $q$. Selain itu, untuk bilangan $p>0, \quad$ apabila $\quad T$ hiponormal- $p \quad$ maka, untuk $0<p<\frac{1}{2}$, $\tilde{T}=|T|^{\frac{1}{2}} U|T|^{\frac{1}{2}}$ hiponormal- $\left(p+\frac{1}{2}\right)$.

\subsection{Saran}

Dalam tulisan ini, penulis hanya membahas mengenai beberapa sifat-sifat hiponormal- $p$ pada ruang Hilbert. Untuk peneliti selanjutnya, diharapkan dapat 
menentukan sifat lain dari operator hiponormal-p pada ruang Hilbert, diantaranya menyelidiki hubungan operator hiponormal-p dengan operator hiponormal- $w$, operator class (A), dan operator paranormal.

\section{UCAPAN TERIMAKASIH}

Pada kesempatan yang baik ini, tidak lupa penulis mengucapkan terima kasih yang sebesar- besarnya kepada yang terhormat Dr. Ch. Rini Indrarti, M.Si yang telah membimbing penulis dalam penyusunan tulisan ini.

\section{DAFTAR PUSTAKA}

Aluthge, A., and Wang, D. 1999. An Operator Inequality Which Implies Paranormality. Mathematical Inequalities and Applications, 2, 113-119.

Berberian, S.K.1961. Introduction to Hilbert Spaces. New York: Oxford University Press.

Cho, M. and Jin, H. 1995. On p-Hyponormal Operators. Nihonkai Math J, 6, 201206.

Furuta, T. 2002. Invitation to Linear Operators. New York: Taylor and Francis.

Furuta, T. 2008. Brief Survey Of Recent Applications Of An Order Preserving Operator Inequality. Taiwanese Journal of Mathematics, 12(8), 21132135.

Horn, R.A and Johnson, C.R.1985. Matrix Analysis. United Kingdom:Cambridge University Press.

Huruya, T. 1997. A Note On p- Hyponormal Operators. Proceedings Of The American Mathematical Society, 125(12), 3617- 3624.

Kreyszig, E.1978. Introductory Functional Analysis with Applications. New York: John Wiley and Sons.

J.Yuan and C.Yang. 2006. Powers Of Class wF(p,r,q) Operators. Journal of inequalities in pure and applied mathematics. 32(7). 